\title{
Biology of Gratiana boliviana, the First Biocontrol Agent Released to Control Tropical Soda Apple in the USA ${ }^{1}$
}

J. C. Medal, D. Gandolfo and J. P. Cuda ${ }^{2}$

\section{Introduction}

Tropical soda apple (TSA), Solanum viarum Dunal (Solanaceae) (Figure 1), is a perennial weed, native to South America, that has spreading throughout Florida at an alarming rate during the last decade. TSA was first reported in Glades County in 1988. This weed is also present in Alabama, Arkansas, Georgia, Louisiana, Mississippi, North Carolina, Pennsylvania, South Carolina, Tennessee, and Texas (Figure 2). Currently, the area infested with TSA is estimated at more than one million acres.

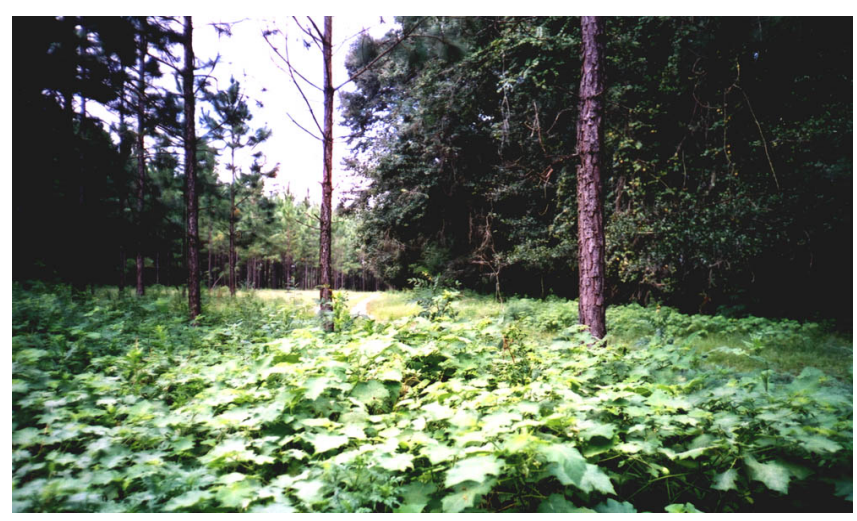

Figure 1. Tropical soda apple in Florida. Credits: Julio Medal, University of Florida

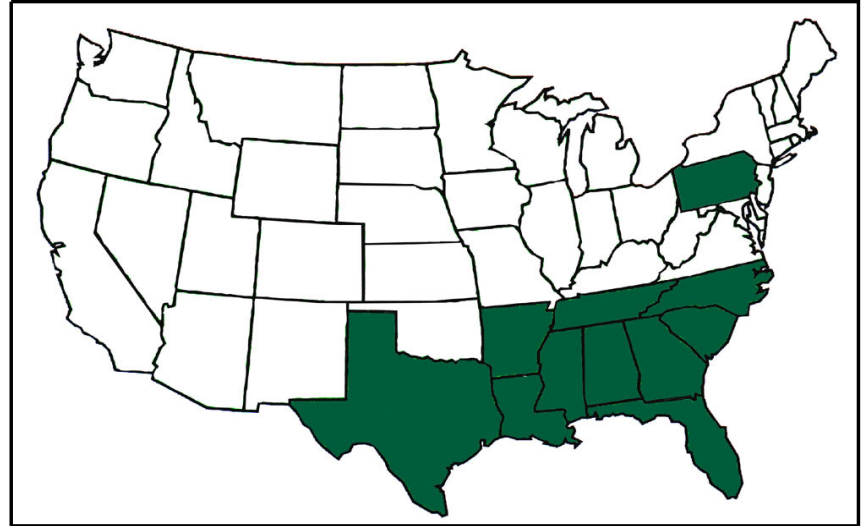

Figure 2. Distribution of tropical soda apple in the USA. Credits: Divina Amalin, USDA/APHIS-University of Florida

\section{First Biocontrol Agent Released in Florida for Tropical Soda Apple}

The TSA leaf beetle, Gratiana boliviana Spaeth (Coleoptera: Chrysomelidae) was approved by the USDA-APHIS-PPQ for field release in Florida on May 7, 2003. The initial release of $G$. boliviana in Florida began in May 14 in Polk County. Subsequent releases were made on June 17 in Alachua County, September 5 in Hendry County, and November 11 in Sumter County. This beetle laid eggs individually (Figure 3) on TSA leaves and petioles. Eggs are initially white in color but turn light green during the

1. This document is ENY-826, one of a series of the Entomology and Nematology Department, Florida Cooperative Extension Service, Institute of Food and Agricultural Sciences, University of Florida. Publication date: November 2003. Please visit the EDIS website at http://edis.ifas.ufl.edu.

2. J. C. Medal and J. P. Cuda, Entomology and Nematology Department, University of Florida, Gainesville, FL 32611 and D. Gandolfo, USDA-ARS South American Biological Control Laboratory, Hurlingham, Argentina.

The Institute of Food and Agricultural Sciences is an equal opportunity/affirmative action employer authorized to provide research, educational information and other services only to individuals and institutions that function without regard to race, color, sex, age, handicap, or national origin. For information on obtaining other extension publications, contact your county Cooperative Extension Service office. Florida Cooperative Extension Service/Institute of Food and Agricultural Sciences/University of Florida/Christine Taylor Waddill, Dean. 
incubation period. Each egg is enclosed by two translucent brown membranes. The egg case is attached to the leaf surface by one extreme. A female can produce on average 300 eggs. Incubation of the egg takes 5-6 days at a temperature of $25^{\circ} \mathrm{C}$.

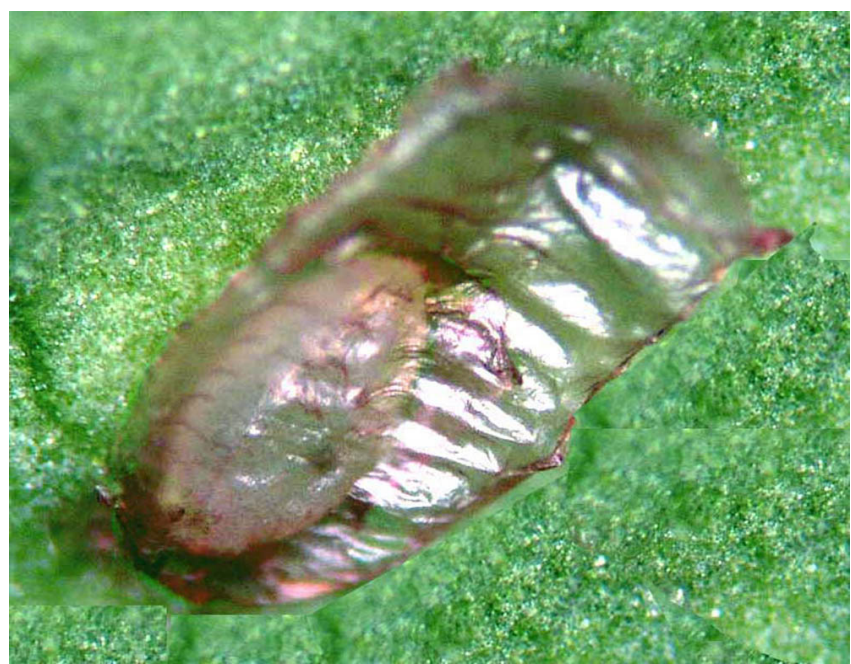

Figure 3. Gratiana boliviana egg. Credits: Divina Amalin, USDA/APHIS-University of Florida

Larvae are cream-colored with a small green spot in the anterior half. Each segment of the body has two lateral processes and a pair of long caudal processes or small forks that arise from the last abdominal segment. Like most tortoise beetles, larvae carry the cast skins on the anal forks with the posterior end of the larva bent forward (Figure 4). The five larval instars can be completed in 15-18 days. Larval feeding is concentrated mostly in the upper third of the plant canopy. Infested plants are easily detected by clusters of small to medium size holes made by the feeding larvae. As feeding progresses, the plants may exhibit large areas of defoliated leaves. Almost complete defoliation has been observed in enclosed cages when the beetle's natural enemies are excluded.

The pupal stage (Figure 5) is completed in about 6-7 days. The pupae are green colored and dorsal-ventrally flattened. Pupae are attached to the leaf by the last abdominal segment. The most common pupation place is the underside of leaves. In severely defoliated plants, some pupae can be found on the petioles and stems.

General coloration of the young adult is light green. Along the margin of the elytra there is a

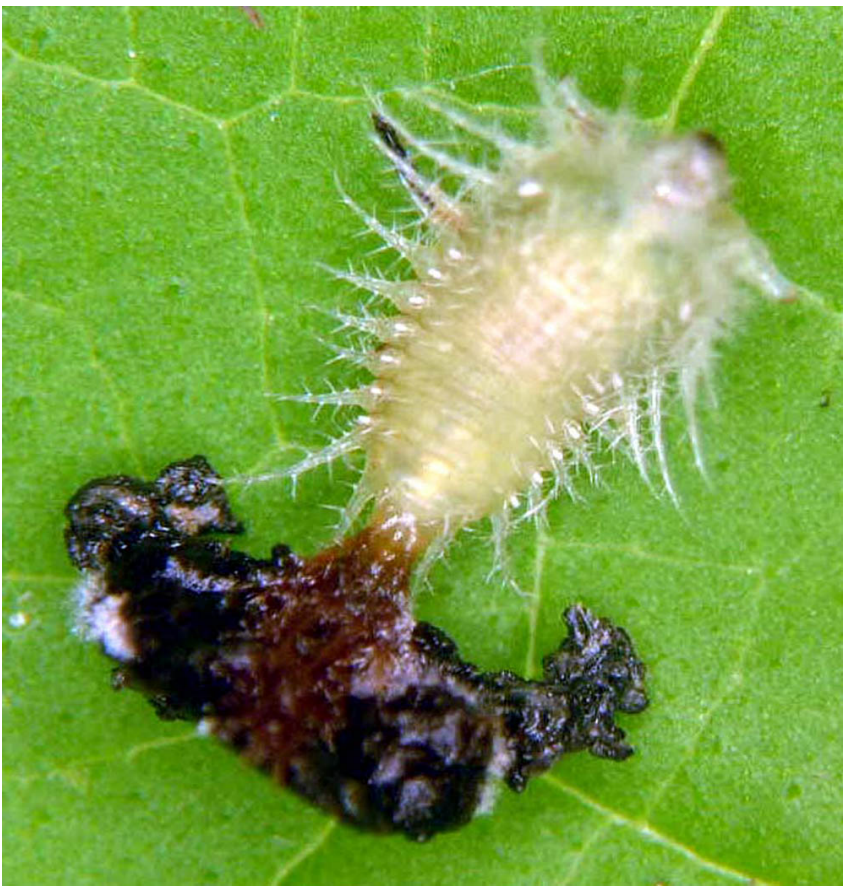

Figure 4. Gratiana boliviana larva. Credits: Divina Amalin, USDA/APHIS-University of Florida

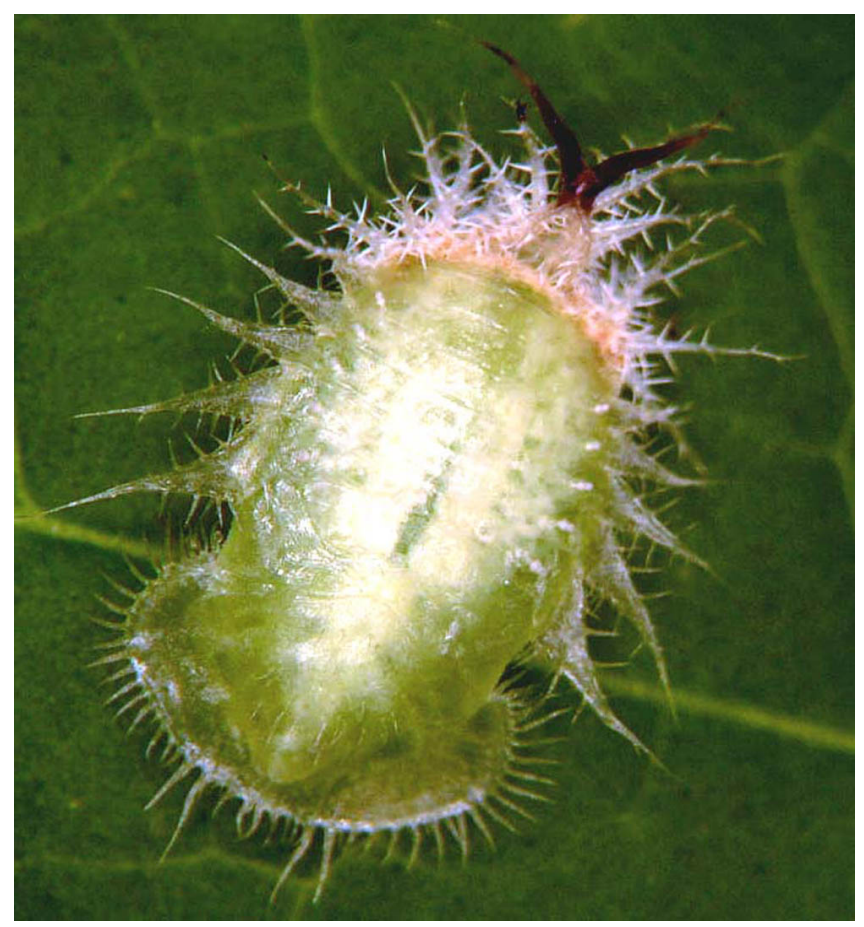

Figure 5. Gratiana boliviana pupa. Credits: Divina Amalin, USDA/APHIS-University of Florida

continous yellow band. The rest of the elytra is light green with irregular yellowish areas between rows or depressions (Figure 6). Mature adults turn a uniform yellow. Females and males can be distinguished by examining the underside of the body. In males, two somewhat rounded orange testes can be observed, 
one on each side of abdomen. In females there is a pair of white ovaries. Characters for separating the sexes can be observed 3-5 days after eclosion. Pre-oviposition period takes from 9 to 12 days. Longevity of females averages 3 months.

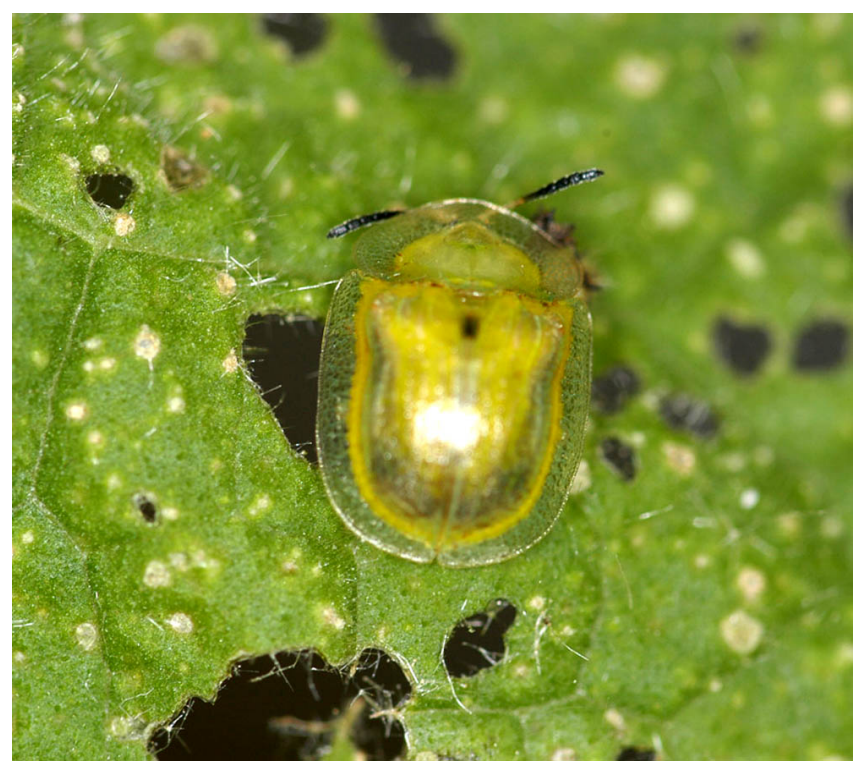

Figure 6. Gratiana boliviana adult. Credits: Divina Amalin, USDA/APHIS-University of Florida

\section{Reference}

Westbrooks, R.G. 1998. Invasive Plants.

Changing the Landscape of America: Fact Book.

Federal Interagency Committee for the Management of Noxious and Exotic Weeds (FICMNEW),

Washington, D.C. 